\title{
La instrucción militar para formar ciudadanos útiles a la nación en la Escuela Industrial Militar de San Luis Potosí durante el porfiriato
}

\author{
Military training to train citizens useful to the nation at the \\ Military Industrial School of San Luis Potosí during the Porfiriato
}

\section{René Alfredo Torres Nava ${ }^{1}$}

\section{Resumen}

Durante el porfiriato se establecieron diversas prácticas pedagógicas dentro del proyecto educativo, uno de ellos fue la instrucción militar tema que ha sido poco explorado. El análisis sobre la función la instrucción militar aporta nuevos enfoques a la historiografía de la educación y al estudio sobre el proyecto de Estado encaminados a la formación de ciudadanos, disciplinados y moralizados.

En este artículo se analiza la instrucción militar dentro del proyecto educativo porfiriano, puntualizando en los siguientes ejes de análisis: cuál era su función y uso dentro de la educación pública, cómo fue llevada a la práctica la instrucción militar, y cuál era el interés por parte del gobierno de San Luis Potosí, en educar a los niños y jóvenes bajo los dispositivos disciplinarios de esta instrucción.

Palabras clave: porfiriato, educación, instrucción y disciplina militar

\section{Abstract}

During the Porfiriato, various pedagogical practices were established within the educational project, one of them was military instruction, a subject that has been little explored. The analysis on the function of military instruction brings new approaches to the historiography of education and to the study of the State project aimed at the formation of disciplined and moralized citizens.

This article analyzes the implementation of military training within the Porfirian educational project, highlighting the following axes of analysis; what was its function and use within public education, 
how military training put into practice, and what was was the interest of the government of San Luis Potosí, in educating children and young people under the disciplinary devices of instruction military. In the first part, we analyze the Porfirian pedagogical project, based on positivism, which permeated the implementation of devices aimed at forming good citizens, with love for the country and useful to the industry. In the second part we examine daily life within the disciplinary methods of military instruction, and in the third part we analyze the role of space as a punitive, disciplinary and teaching place.

\section{Keywords: Porfiriato, education, instruction and military discipline}

\section{Introducción}

Durante el porfiriato la educación fue una herramienta que permitió formar a las nuevas generaciones de ciudadanos trabajadores, sanos, disciplinados, útiles a la nación. La élite política porfiriana, bajo la influencia del positivismo, reconoció la necesidad de instituir la educación pública como un instrumento de cohesión social y abatir el analfabetismo que se presentaba en la mayor parte de la sociedad mexicana.

A través de la educación de "las masas se lograría una sociedad progresista," es decir, ciudadanos alfabetizados, con deberes sociales, industriosos, autónomos y trabajadores. (Baranda, 1889: 1-20). El discurso oficial afirmaba que los planteles públicos con educación elemental y las escuelas de artes y oficios, prepararían ciudadanos capaces de participar en el desarrollo económico y proponer soluciones a los problemas de atraso y de pobreza presentes en el país. (AHESLP, SCG, 1892.2).²

Dentro del proyecto educativo porfiriana se buscó también infundir en la niñez, el amor a la patria, el conocimiento de los recursos naturales y la riqueza cultural del pasado prehispánico, con la enseñanza de la geografía, y la historia de México, también la instrucción militar fue el método pedagógico para inducir a los alumnos los valores patrios, la disciplina, el civismo y el mejoramiento del estado físico de los alumnos.

El análisis sobre los métodos pedagógicos impulsados en la Escuela Industrial Militar aporta nuevos enfoques a la historiografía de la educación. Podemos apreciar la importancia y el impulso a la instrucción militar, y las estrategias para formar la idea del trabajo, la disciplina laboral, el amor a la patria, los hábitos de la limpieza y la salud y el impacto que esta formación tuvo en un sector de la sociedad en San Luis Potosí.

La hipótesis planteada en este artículo sostiene que la Escuela Industrial Militar de San Luis Potosí fue un espejo del proyecto pedagógico porfiriano, basado en el positivismo, que

\footnotetext{
${ }^{2}$ Archivo Histórico del Estado de San Luis Potosí.
} 
buscó la inserción de la niñez y juventud en el desarrollo industrial del país. A través este espejo se observa la intención del régimen porfiriano por convertir a México en una nación moderna y la educación representaba una de las herramientas para lograrlo. A través de la educación y los métodos disciplinarios como la instrucción militar se formarían los buenos ciudadanos que el país requería.

Para desarrollar este artículo se analizó el discurso realizado por el Estado en relación a la importancia de la educación y los proyectos llevados a cabo. Se revisaron diversas fuentes documentales, como son: memorias de gobierno, el Periódico Oficial de San Luis Potosí, los boletines pedagógicos, la correspondencia entre los padres de familia y la dirección de la Escuela Industrial Militar, así como la correspondencia entre los funcionarios de la misma Escuela con el gobierno potosino. Las fuentes documentales principalmente se localizan en el Archivo Histórico del Estado de San Luis Potosí, y corresponden a los fondos de Secretaría General de Gobierno y Ayuntamiento de San Luis Potosí, de 1877 a 1911. Además, se examinó la obra de Bernardo Reyes, Ensayo sobre un nuevo sistema de reclutamiento para el ejército y organización de la Guardia Nacional, en la cual plasmó su proyecto sobre establecer la instrucción militar en las escuelas públicas del país.

En el primer punto se aborda el proyecto pedagógico porfiriano, basado en el positivismo, que permeó en la implementación de dispositivos encaminados a formar buenos ciudadanos, con amor a la patria y útiles a la industria. En la segunda parte examinamos la influencia de Bernardo Reyes en el proyecto de la instrucción militar en la educación pública, en el tercer apartado se explica cómo estaba organizada la Escuela Industrial Militar, a partir de grados militares y compañías, y en el último punto se analiza la vida cotidiana, la instrucción militar con arma y los métodos disciplinarios.

\section{La instrucción militar en las escuelas públicas durante el porfiriato}

El movimiento ilustrado que se produjo en Europa durante el siglo XVIII y principios del XIX, y la Revolución Industrial, plantearon la necesidad de formar mano de obra disciplinada con dominios técnicos para la industria. El término revolución industrial fue usado originalmente por los franceses en los primeros años del siglo XIX para resaltar la importancia de la mecanización de su industria, y equipararla con la revolución de 1789. (Cameron, 1997: 34-35).

Según Edward P. Thompson, la Revolución Industrial y el nacimiento del trabajo fabril originaron cambios culturales, como lo fue la economía del tiempo. Es decir, la producción fabril expansiva, llevó a establecer horarios laborales rígidos. Para lograr la economía del tiempo fue necesario utilizar en las escuelas métodos disciplinarios y correctivos. Además, la economía del tiempo fue un tema planteado por el Estado británico, como una necesidad 
para terminar con la vagancia, el ocio y los vicios; la escuela inculcó a los niños este concepto, se les enseñó el hábito de la puntualidad y el trabajo, y se les habituó a una nueva representación cultural en el universo del tiempo disciplinado. (Thompson, 1979: 239-293).

Pierre Bourdieu y Jean Claude Passeron, plantean que a través de los sistemas educativos se ejerce un dominio simbólico, en relación a la distinción de las capacidades escolares de los alumnos. Cada acción pedagógica tiene, pues, una eficacia diferenciada en función de las diferentes caracterizaciones culturales preexistentes de los sujetos y que son de naturaleza social. La escuela, al sancionar estas diferencias como si fueran puramente escolares, contribuye al mismo tiempo a reproducir la estratificación social y a legitimarla asegurando su interiorización y persuadiendo a los individuos de que ésta no es social, sino natural. (Bourdieu y Passeron, 1996: 18-19).

Los mismos autores también refieren que la educación establece una relación de violencia simbólica, la cual genera desigualdades sociales. Sobre esta reflexión, los autores señalan que la acción educativa construye una forma particular de pensar, de hacer y de actuar. A su vez, la educación reproduce un capital cultural en la sociedad; esto se refleja en las desigualdades entre las clases sociales, en donde los títulos culturales-educativos ejercen un dominio simbólico. Según Bourdieu, la reproducción cultural es un proceso en el cual un grupo como la burguesía francesa mantiene su posición en la sociedad a través de un sistema educativo que se presenta autónomo e imparcial, mientras que de hecho selecciona para la educación superior a estudiantes con las cualidades inculcadas desde el nacimiento de este grupo social. (Bourdieu y Passeron, 1996: 18-19).

Desde el punto de vista de Michael Foucault, desde el poder se instituyen mecanismos y dispositivos que ejercen dominación y control social. Según el autor, la formación de la disciplina y el castigo son usados por la autoridad como tácticas políticas que generan una acción social de manera controlada. O bien, a través del poder, se determina una actitud de respeto a las reglas que regulan las conductas de los hombres. Para Foucault, a través de las escuelas se establecen estos dispositivos para formar cuerpos sometidos y ejercitados, cuerpos "dóciles". Mediante la disciplina escolar se van ejerciendo los mecanismos de dominio necesarios para establecer la obediencia en el trabajo, tanto en las fábricas como en los talleres. (Foucault, 2002: 79-81).

En este sentido podemos entender la disciplina como "una anatomía política del detalle" en el ámbito de la pedagogía escolar, como forma de encauzamiento de la conducta. Pone especial énfasis en las pequeñas cosas, en su observación para el control y la utilización de los hombres a través de la minucia de los reglamentos, la mirada puntillosa de las inspecciones, la sujeción a control de las menores partículas de la vida y del cuerpo. (Foucault, 2002: 79-81).

Discurriendo sobre estos planteamientos podemos analizar que en la Escuela Industrial Militar. La disciplina tuvo un papel fundamental en la educación del ciudadano que el 
Estado aspiraba. Es decir, se buscó la formación de alumnos de forma integral; la escuela se encargó de establecer los dispositivos simbólicos como la obediencia, disciplina, competencia, y productividad, que más tarde fueran utilizados en las distintas estructuras laborales.

El crecimiento industrial durante el porfiriato generó la necesidad de formar técnicos industriales, pero a su vez, estos técnicos tendrían que ser moralizados y disciplinados, para lo cual la instrucción militar representaba la herramienta más eficaz. (Bazant, 1993: 12-30). También a través de la escuela el régimen divulgó las prácticas de la buena salud e higiene personal, formación de la disciplina, hábito del trabajo y buenas formas al hablar, vestir y comer. (Torres, Septién, 1998: 13-15).

El gobierno de Porfirio Díaz formó cruzadas para regenerar a los vagos y viciosos, encauzándolos hacia el bien, para ello la educación era la principal herramienta. La instrucción y disciplina militar permitirían crear al ciudadano que el país requería. (Mirando, 2006: 10-34). En este sentido, la elite dominante se preocupó por la regeneración de los indígenas, vagos, ociosos, y menesterosos; la educación fue "una de las herramientas básicas con la que los grupos dirigentes imaginaron resolver todos los problemas del país a lo largo del siglo XIX, llegándola a concebir como una especie de panacea social." (Castillo, 2006: 15-20).

De esta manera la instrucción militar fue parte del proyecto pedagógico porfiriano, basado en el positivismo, como una herramienta para formar a los ciudadanos que el país requería; se pensaba que a través de "los ejercicios y la práctica militar, se favorecería el desarrollo físico de los niños, y despertaría en su noble corazón el sentimiento del patriotismo." (POESLP, 7 de abril, 1886). Dicho sentimiento, las tácticas militares y la enseñanza en el uso de armas, formarían ciudadanos para defender la patria y sus instituciones cuando la nación se encontrara en peligro. (POESLP, 7 de abril, 1886).

También la instrucción militar favorecería a la disciplina y a la formación de ciudadanos con una educación asociada al buen comportamiento social, a la obediencia y disciplina laboral.

El régimen porfiriano se inspiró en la enseñanza castrense que se daba en las escuelas francesas desde 1789, cuando Napoleón Bonaparte formalizó la instrucción militar en las escuelas públicas como una necesidad de contar con elementos preparados para sus fuerzas. También de las escuelas norteamericanas que, durante el siglo XIX, enseñaban a los alumnos ejercicios y tácticas militares para formar lealtad a la patria.

Para el régimen porfiriano, la instrucción militar en las escuelas públicas fue una de las herramientas con la cual se fomentó la lealtad, el patriotismo y el orgullo nacional en los ciudadanos. El hecho de rendir culto a la bandera nacional, y proteger a las instituciones y al Estado, representaba el camino con el cual se construía la nación, así como ciudadanos comprometidos con el país. (POESLP, 8 de abril, 1884). 
Es importante mencionar que la instrucción militar fue un sistema practicado en algunas instituciones educativas en México, entre ellas, las escuelas correccionales y algunos planteles de educación elemental, como también de artes y oficios. (Bailón, 2012: 13-14). Sin embargo, hubo planteles en donde los alumnos recibían instrucción en el manejo de armas y la estructura era por grados militares, a diferencia de las escuelas en donde sólo se practicaban ejercicios militares.

El gobernador Carlos Díez Gutiérrez en su informe de 1884 destacó que después del Colegio Militar, la Escuela Industrial Militar de San Luis Potosí fue la primera institución de enseñanza industrial del país en donde desde 1883 se instruía a los alumnos en las artes militares. El gobernador compró 200 fusiles de la misma categoría de los que "se utilizan en las escuelas industrial militares en Francia”. (POESLP, 7 de abril, 1884).

En el siguiente punto de aborda cómo se establece la instrucción militar en las escuelas públicas del país a través de la influencia del general Bernardo Reyes como uno de los principales promotores de esta instrucción.

\section{La influencia de Bernardo Reyes en la educación militar}

Uno de los principales promotores de la instrucción militar en las escuelas públicas fue el general Bernardo Reyes quien, durante el gobierno de Porfirio Díaz, ocupó diversos cargos públicos, entre ellos, se hizo cargo de la comandancia militar en Nuevo León y fue gobernador provisional de este estado de 1885 a 1887. Fue gobernador constitucional del mismo estado en 1889 y secretario de Guerra y Marina de 1900 a 1902 y nuevamente gobernador de Nuevo León de 1902 a 1909. También estuvo en San Luis Potosí para intentar apaciguar la rebelión indígena de Juan Santiago en la Huasteca potosina hacia 1879 y en esta plaza fue jefe de la $6^{a}$ zona militar entre 1881 y 1883. Reyes recomendó al gobernador Carlos Díez Gutiérrez impulsar la instrucción militar en las escuelas públicas. Este proyecto se llevó a cabo tanto en la Escuela Industrial Militar como en la Escuela Normal para Varones, a partir de 1883. Después sería formalizado en las escuelas públicas del estado, con la ley del 30 de mayo de 1884. (POESLP, 26 de septiembre, 1884). San Luis Potosí fue el primer estado de la república en donde se formalizó la instrucción militar en las escuelas públicas de manera obligatoria.

Tanto para el gobernador Díez Gutiérrez como para el general Reyes, la enseñanza militar en las escuelas públicas formaría ciudadanos útiles e integrales, asimismo se presentaba como una alternativa para contar con soldados profesionales al servicio de las armas en la defensa del país. (POESLP, 7 de abril, 1884). 
La cuestión de higiene, de subordinación y disciplina, así como la conveniencia de formar no solo buenos ciudadanos, sino instruidos en lo posible en la ciencia de la guerra, para que sus servicios en las armas sean más eficaces a la patria en época en que peligren sus autonomía o libertad, hacían ya indispensable una reforma de este género, aceptada desde hace tiempo en algunas naciones europeas. Hasta ahora no ha sido posible dar a este nuevo ramo de enseñanza, todo el ensanche debido por la falta de instructores y de elementos a propósito en cada uno de los establecimientos; pero se ha puesto en práctica en la Escuela Normal para profesores y en la Industrial Militar. (POESLP, 21 de septiembre 1885).

La idea del general Reyes de establecer la instrucción militar en las escuelas públicas del país fue plasmada en su obra titulada, Ensayo sobre un nuevo sistema de reclutamiento para el ejército y organización de la Guardia Nacional. (Reyes, 1885: 48-49). En esta obra exponía que era necesario implantar en las escuelas públicas un régimen semi-militar, lo que permitiría formar en los infantes sentimientos patrióticos y una verdadera vocación en el servicio de las armas. Con la instrucción militar desde la edad infantil se prepararían ciudadanos al servicio de la patria y además se revitalizaría al ejército con elementos de verdadera vocación que tuvieran aprecio a la clase militar y que no desdeñaran pertenecer a ella. (Reyes, 1885: 50).

Según Reyes, dicha instrucción no sólo formaría militares de carrera (ya fuesen soldados rasos, oficiales o jefes), sino que tenía también como propósito formar en las mentes de la niñez y juventud mexicana una serie de valores cívico-marciales tendientes a generar un sentimiento de unidad y amor a la patria, y por consiguiente, el deseo de defenderla cuando estuvieran en peligro su territorio, autonomía o instituciones. (Reyes, 1885: 48-49).

También el General Bernardo Reyes mencionaba que el grueso del ejército mexicano carecía por completo de identidad patriótica y no tenía las más mínimas nociones de instrucción militar, debido a que la mayoría de los soldados eran reclutados mediante la leva para el servicio de las armas. Es decir, el reclutamiento forzoso que realizaban regularmente los jefes políticos de los partidos, con el fin de deshacerse de criminales, alcohólicos, vagos, tahúres y, en general, de cualquier individuo que pudiera resultar "pernicioso" para los intereses de una región o población dada. (Ramírez, 2008: 183-219).

Reyes era partidario de un ejército menor pero patriótico y profesional, preparado en las aulas escolares, en donde se inculcarían los principios cívicos nacionales, más que de un ejército gigantesco compuesto por cuadros no profesionales, es decir (jornaleros, mendigos, vagos) reclutados por medio de la leva y liderados por caudillos militares.

El proyecto planteado por Bernardo Reyes para integrar en la educación pública la instrucción y los ejercicios militares se instituyó como obligatorio en la Ley reglamentaria de instrucción obligatoria en el Distrito Federal y Territorios del país del 3 de junio de 1896. En ella se estableció que la instrucción militar (para hombres) y la gimnasia (para mujeres) eran obligatorias. 
El plan general consistía en emplear las horas en que no había ocupación expresa en los alumnos, para iniciarlos de modo ameno en las prácticas militares y ejercicios tácticos, lo cual haría posible contar con cuerpos sanos y viriles. Con ello, las autoridades proyectaban formar en la niñez y juventud cuerpos vigorosos y desarrollar condiciones saludables, intelectuales y morales en los alumnos, lo cual contribuiría a alejar a la niñez de los vicios, del juego y del ocio. (Moreno y Kalbtk, 1981: 53).

La instrucción militar en las escuelas públicas se dividió en tácticas y ejercicios militares con arma y sin arma. En la gran mayoría de los planteles de educación elemental sólo se incluyeron ejercicios militares, debido a la falta de presupuesto en los estados, ya que se tendría que invertir en instructores militares, fusiles, espadas, marrazos, y uniformes militares, por lo que resultaba costoso el sostenimiento de los batallones infantiles en las escuelas públicas. (Congreso Nacional de Educación Primaria, 1912).

La instrucción militar con arma se impartió en las escuelas de artes y oficios e industrial militares, en dónde se prepararon técnicos con conocimiento en el arte de las armas para integrarlos al ejército federal. Los alumnos destacados de estas instituciones podrían continuar sus estudios en el Colegio Militar. Entre las escuelas que fueron creadas con este fin resaltan la Escuela Industrial Militar de San Luis Potosí, en la cual desde 1883 se instruía el arte castrense a los alumnos, y la Escuela Industrial Militar "Porfirio Díaz" de Morelia, desde 1885. (Ordenanzas Generales del Ejército y Armada de la República Mexicana, 1899).

En este contexto, es claro que el régimen porfiriano fue cambiando el sistema de reclutamiento para el ejército. Si bien por lo general los jóvenes de las clases vulnerables que delinquían eran enrolados en el ejército federal como reservas, quienes cumplían con la función de apaciguar cualquier rebelión o huelga. También resguardaban las instituciones del Estado, industrias o caminos ferrocarrileros.

El régimen proyectó formar por medio de la educación un ejército profesional preparado en las aulas y campos de entrenamiento militar. Es decir, el hecho de otorgar educación militar a los niños y jóvenes de la clase menesterosa permitía formar soldados con conocimientos técnicos militares, como el manejo y destreza con el fusil, espadas y marrazos, lo cual hacía más efectivo el desempeño del ejército ante cualquier rebelión, defensa de las instituciones y de la nación. (Reyes, 1885). A su vez, el hecho de formar alumnos con vocación al servicio del estado y amor al país, se contaría en cada alumno "un soldado, para el día que amenace algún peligro a la patria”. (POESLP, 25 de septiembre, 1890).

La instrucción militar también fue visualizada por el régimen como la herramienta con la cual se lograría obtener un control social ante las posibilidades de que los niños y jóvenes de los sectores vulnerables pudieran delinquir o ser perniciosos para la sociedad. A través de 
la disciplina militar se formarían ciudadanos con una educación asociada al buen comportamiento social y a las necesidades laborales. (Ojeda, 2006: 12-20).

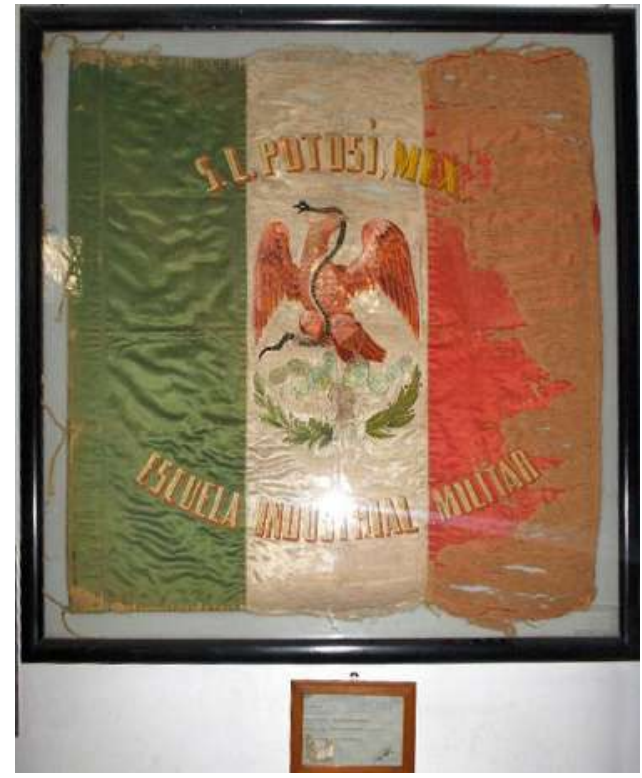

Imagen I. Banderín de la Escuela Industrial Militar Fuente: AHIDC, SLP, 1895

En el banderín de la Escuela Industrial Militar se representó el escudo nacional utilizado durante el porfiriato en el cual el águila aparece de frente, con la cabeza levantada y ligeramente de perfil, con las alas extendidas, devorando una serpiente y posada sobre un nopal rodeada por dos laureles, como señal de victoria. (Secretaria Armada de México, 1970: 9-13).

La instrucción militar tenía como propósito: a) La formación de oficiales (científicos) dentro del Colegio Militar. b) La alfabetización de los soldados. c) La instrucción teóricopráctica de los oficiales y la creación de nuevas escuelas especializadas, como lo fue la Escuela Militar de Aspirantes y las Escuelas Industrial Militares d) La obligatoriedad de la instrucción militar en las escuelas primarias. (Secretaría de la Defensa Nacional, 1997: 10-11).

Cabe señalar que la obligatoriedad de dicha instrucción en las escuelas públicas fue retomada durante la época revolucionaria, en particular en la época carrancista, tiempo en que se decretó que, en las escuelas primarias, superiores y preparatorias de toda la República, la instrucción militar para los varones y la enseñanza de enfermería para las mujeres era obligatoria. (POESLP, 1916: 1-4). 


\section{La organización de la Escuela Industrial Militar}

Los alumnos de la Escuela Industrial Militar fueron educados con una estricta disciplina militar basada en las Ordenanzas del Ejército Mexicano, a partir de lo cual se establecieron los códigos de conducta, los premios y castigos, las tácticas y ejercicios militares. (Código Militar, 1899: 8-20).

La organización en la Escuela estaba dividida en grados militares: soldado cabo, sargento segundo, sargento primero, subteniente, teniente, capitán segundo, capitán primero, mayor, teniente coronel, coronel, general de brigada y general de división. Estos grados se asignaban de acuerdo a la disciplina, aprovechamiento, actitud y tiempo en el servicio. (AHESLP, SCG, Reglamento de la Escuela Industrial Militar, 1894).

Tabla 1

\begin{tabular}{|c|c|}
\hline \multicolumn{2}{|c|}{ Jerarquías y clases militares } \\
\hline $\begin{array}{c}\text { Soldado, cabo, sargento segundo, } \\
\text { sargento primero }\end{array}$ & Tropas \\
\hline Teniente coronel, coronel & Oficialidad \\
\hline General de brigada, general de división & Jefes \\
\hline
\end{tabular}

Fuente: elaboración propia con base en el Reglamento de la Escuela Industrial Militar, 1894.

La unidad militar de dicha institución estaba conformada por dos compañías, la primera estaba formada por 1 sargento primero, 1 sargento segundo, 2 cabos, 42 integrantes de la banda militar y 42 soldados, con un total de la tropa de 88 integrantes. La segunda la integraban 1 sargento primero, 1 sargento segundo, 2 cabos, 45 integrantes de banda militar y 42 soldados, un total de tropa de 91 soldados. El total de las dos compañías militares era de alrededor de 170 a 200 integrantes. (AHESLP, SGG, 1898.13).

Las dos compañías de la Escuela Industrial Militar formaban parte de la artillería estatal potosina, la cual estaba organizada de la siguiente manera:

Tabla 2

\begin{tabular}{|c|c|}
\hline \multicolumn{2}{|c|}{ Artillería del Estado de San Luis Potosi } \\
\hline Plana Mayor del Estado & 25 elementos \\
\hline Primer Batallón & 25 elementos \\
\hline Segundo Batallón & 20 elementos \\
\hline
\end{tabular}




\begin{tabular}{|c|c|}
\hline Tercer Batallón (Plana Mayor del Estado) & 53 elementos \\
\hline Gendarmes (Ciudad de San Luis Potosí) & 20 elementos \\
\hline Policía Montada (Ciudad de San Luis Potosí) & 18 elementos \\
\hline $1^{a}$ Compañía Escuela Normal para Profesores & 77 elementos \\
\hline $2^{a}$ Compañía Escuela Normal para Profesores & 80 elementos \\
\hline I Compañía Escuela Industrial Militar & 88 elementos \\
\hline $2^{a}$ Compañía Escuela Industrial Militar & 91 elementos \\
\hline
\end{tabular}

Fuente: elaboración propia con base de la Revista de los batallones de San Luis Potosí. Por el General Brigadier Pedro A. González, Jefe de la 6a zona militar 1898. (AHESLP, SCG, 1898.13).

Por el hecho de que ambas compañías militares de la Escuela Industrial Militar formaran parte de artillería de San Luis Potosí, estaban comprometidas a proteger las instituciones del estado, para lo cual los soldados que conformaban la tropa realizaban guardias en los edificios de gobierno y plazas públicas. Por ello, los soldados de ambas compañías de la Escuela Industrial Militar recibían un salario mensual 2 pesos con 80 centavos, excepto los sargentos de tropa, quienes recibían 3 pesos con 10 centavos. En total, el Ejecutivo potosino pagaba a los miembros de las compañías militares de la Escuela Industrial Militar alrededor de 560 pesos mensuales. (AHSLP, SGG, 1898.13).

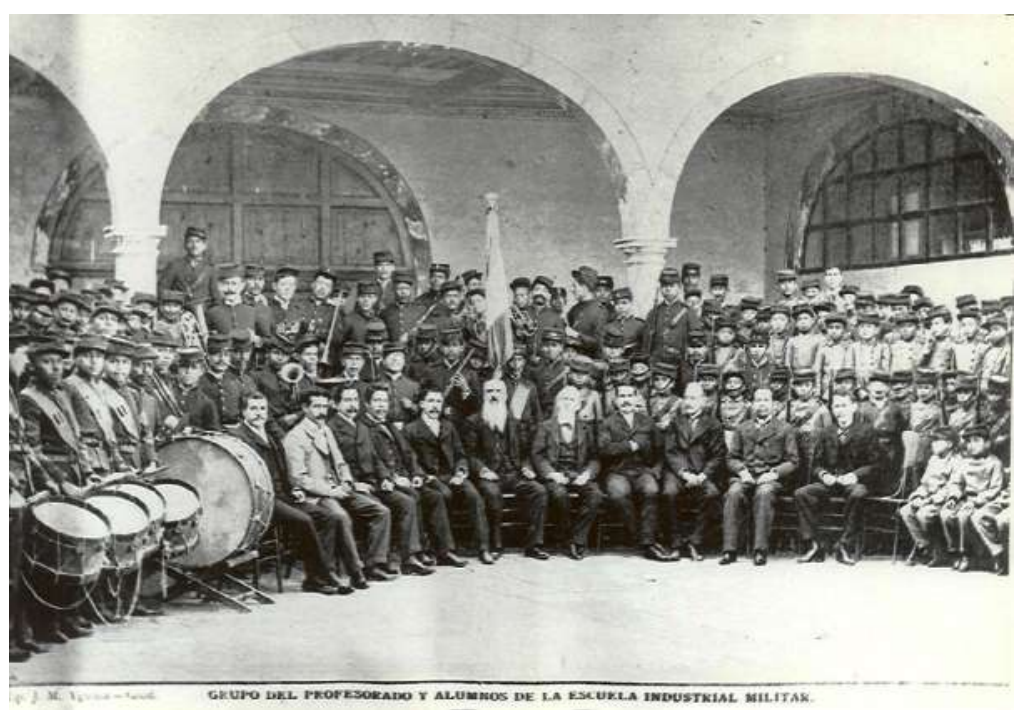

Imagen II. Profesores y alumnos de la Escuela Industrial Militar, ca, 1890.

Fuente: AHESLP, Colección fotográfica. 
En esta imagen se observa el grupo de profesores de la Escuela Industrial Militar. Destaca el uniforme de gala que portaban los alumnos que integraban la banda militar de la institución. También se observa a los alumnos integrantes de las compañías con fusil en mano, entre ellos se distinguen algunos niños de muy corta de edad, los cuales pudieron haber tenido entre 8 y 12 años, por la edad de ingreso al plantel. Esta fotografía fue tomada en el exconvento de San Agustín acondicionado para albergar el plantel educativo.

En el uniforme que usaban los alumnos de la institución portaba las iniciales E.I.M. y se conformaba de chaqueta y pantalón de paño para el interior del establecimiento; así como chaqueta y pantalón de lienzo o paño y gorra especial según el evento público en donde participaran los estudiantes. Tanto este uniforme como la ropa interior eran fabricados en los talleres de la institución. (AHESLP, Reglamento de la Escuela Industrial Militar, 1894).

La banda militar participaba en un gran número de eventos importantes para el gobierno, como los informes del Gobernador, el desfile de inauguración del Ferrocarril Nacional Mexicano en la ciudad de San Luis Potosí, (POESLP, 17 de noviembre 1888) y la misma inauguración del edificio del Centro Agrícola e Industrial Potosino celebrada el día 15 de septiembre de 1907. (POESLP, 15 septiembre 1907).

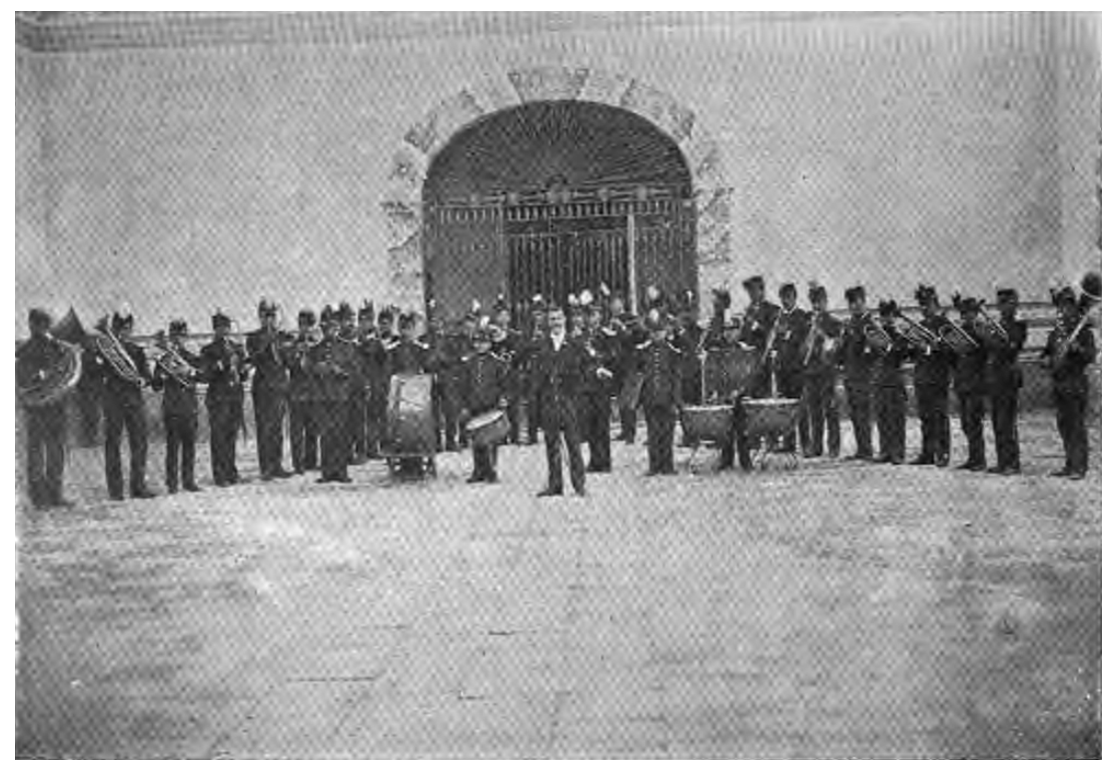

Imagen III. Banda de la Escuela Industrial Militar, Ca. 1899.

Fuente: Muro, 1889: 207. 
Los alumnos que integraban las compañías militares y la banda militar recibían un salario por tocar en los edificios de gobierno, plazas públicas y eventos civiles, de 37 centavos a 1 peso. El hecho de otorgar un salario a los integrantes de las compañías de la Escuela Industrial Militar refleja la importancia que adquirió para el gobierno estatal contar con militares profesionales a su servicio, como también para motivar a los alumnos a permanecer en ella. Los alumnos más destacados, disciplinados y con habilidad militar podrían aspirar a ocupar plazas como sargentos en la Plana Mayor de las tropas del estado. Por ejemplo, Albino Pérez e Ignacio Galindo, quienes ocupaban los puestos de sargento primero y segundo en las compañías de la institución, fueron nombrados con el mismo grado militar en la misma. (AHESLP, SCG, 1898.13).

La educación en la Escuela Industrial además de dar oportunidad a los alumnos de formar parte de la artillería castrense de San Luis Potosí, también les permitía continuar sus estudios en el Colegio Militar de la Ciudad de México. Entre ellos, Ezequiel Navarro y Carmen Ramos, quienes eran subtenientes de la $l^{\text {a }}$ compañía de la Escuela, y los sargentos, Servando López, Ángel Sierra y Federico González, miembros de la $2^{a}$ compañía, quienes fueron enviados por parte del gobierno estatal para continuar su carrera en este Colegio. Para obtener el grado de sargento, por lo menos tenían que cumplir 4 años en la compañía de la Escuela Industrial. (AHESLP, SGG, 1894.4).

En el siguiente apartado se explican detalles sobre cómo era la vida cotidiana en el plantel, la instrucción militar y los métodos disciplinarios, también se indaga sobre la forma cómo percibían los alumnos la educación y disciplina militar.

\section{La vida cotidiana en la Escuela Industrial Militar y la instrucción militar con arma}

El reglamento de la Escuela Industrial Militar y los comunicados del director de la institución al Gobernador de San Luis Potosí, nos brindan a un acercamiento a la vida cotidiana en la institución, las estrategias para la formación de soldados al servicio de la patria, y sobre todo, la percepción de los alumnos sobre la instrucción militar. Asimismo, a través del análisis de la prensa potosina, como El Estandarte o El Periódico Oficial, y de la correspondencia entre los padres o tutores de los alumnos con el director de la institución, se puede percibir la imagen de la Escuela Industrial Militar y la formación militar en los alumnos, desde fuera de la institución.

La vida cotidiana en la institución comenzaba desde las 5 a.m., cuando se tocaba la diana. A ese toque, todos los alumnos se tenían que levantar, asear sus personas y dormitorios, para después vestirse con su uniforme militar y formarse en pelotones frente a la puerta de sus respectivos salones para pasar revista de vestuario. Los sargentos de cada pelotón 
tomaban nota de roturas de los uniformes, falta de botones o de cintas, lo cual era reportado a la dirección. Estas faltas eran castigadas en lo privado; otras sanciones incluían la disminución de su ración cotidiana de pan, o no dejándolos salir francos algún día festivo o se les asignaban tareas de limpieza en los edificios públicos.

Posteriormente, de 6 a.m. a 7 a.m., pasaban al patio a realizar la instrucción militar y gimnasia. (AHESLP, Colección de leyes y decretos, 1877-1902). Después, los alumnos se dirigían a los comedores a desayunar y a partir de las 8 a.m. cursaban la instrucción primaria hasta las 12 p.m. Posteriormente tomaban un "rancho" termino que refería a la reunión de grupo de personas para comer en forma de rueda se empleaba regularmente para soldados. Posteriormente de 1 p.m. a 2 p.m. cursaban la clase de dibujo. De 2 p.m. a 3 p.m. tomaban la clase de inglés y de 2 p.m. a 5 p.m. se preparaban en los talleres de herrería, fundición, mecánica y dibujo industrial, zapatería, carpintería, imprenta. (AHESLP, Colección de leyes y decretos, 1877-1902).

Por la noche, después del toque de silencio, no se les permitía vagar por los patios y se les castigaba cuando el motivo para hacerlo no se justificaba. Todas las noches se hacía la inspección de los dormitorios y se despertaba a los que se habían dormido sin quitarse el uniforme, sin descalzarse o sin poner sus ropas en los clavijeros que cada uno tenía en lo alto de la cabecera de su catre.

Los sábados, de las 6 a.m. a las 9 a.m. se dedicaban a la práctica de tiro al blanco, simulacros de combate, tácticas y ejercicios militares, en un lugar que se conocía como el Llano de Paredes. Posteriormente se realizaba el aseo de armamento y vestuarios, para finalmente pasar revista. (AHESLP, Colección de leyes y decretos, 1877-1902).

Acerca de los ejercicios militares, el punto fundamental era ejercitar el cuerpo de los niños y hacerlos más vigorosos. Para ello se realizaban competencias atléticas, saltos de longitud, ejercicios para educar la vista y el puño (defensa personal), lanzamiento de discos a puntos señalados y ejercicios en argollas volantes. (Congreso Nacional de Educación Primaria, 1912).

Los domingos, después del aseo, cambiaban de ropa, pasaban revista y desayunaban. Los alumnos francos, es decir el día libre que tenían los integrantes de las compañías militares salían de paseo con sus familias y los huérfanos que carecían de persona con quien salir, "iban acompañados por una persona de moralidad a juicio del director o del prefecto." (AHESLP, Colección de leyes y decretos, 1877-1902). Tanto en la Escuela Industrial Militar como en la Escuela Normal para Profesores, la instrucción militar estaba a cargo de coroneles y capitanes formados en el Colegio Militar de la ciudad de México, como el coronel Mariano Moctezuma, quien preparaba a los alumnos en relación las tácticas y disciplina militar en 1885. (AHESLP, Colección de leyes y decretos, 1877-1902). 
Para llevar a cabo la instrucción con arma, el gobernador Carlos Diez Gutiérrez compró doscientos fusiles de tiro y doscientos para ejercicio de tipo Chassepott, fusil utilizado en las escuelas militares francesas para enseñar el tiro al blanco, maniobras militares y que eran de un tamaño adecuado para dichos jóvenes. (POESLP, 8 de abril 1884).

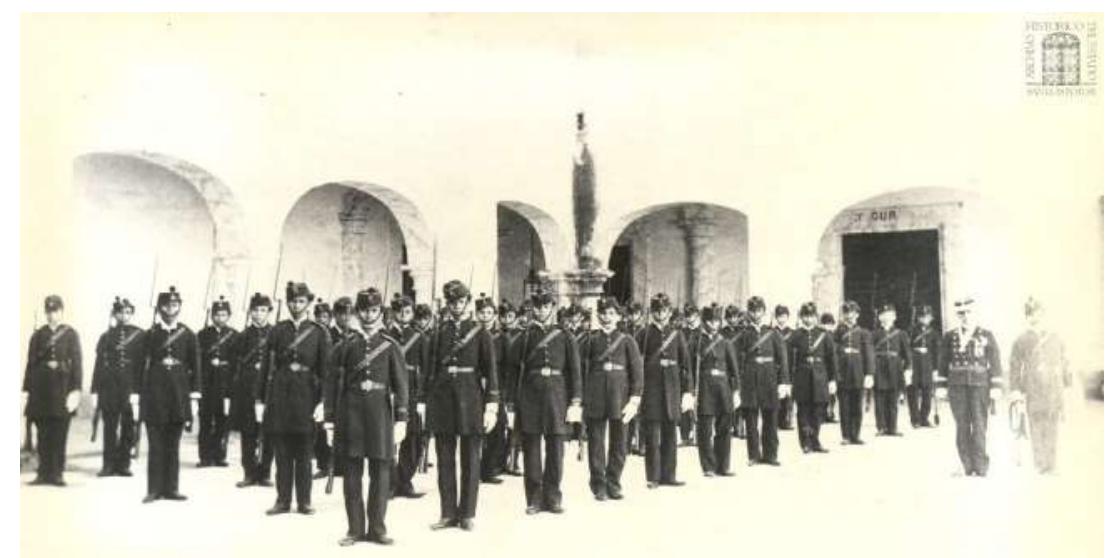

Imagen IV. Compañía militar de la Escuela Industria Militar. Ca. 1890 Fuente: AHESLP, Colección fotográfica.

En esta imagen se observa la formación y la postura militar de los alumnos y su uniforme de gala acompañado de kepis y guantes blancos. También destaca el fusil con bayoneta, lo cual representa una compañía militar equipada y profesional. Destaca el apoyo económico por parte del gobierno estatal para mantener provista a las compañías de la Escuela Industrial Militar.

Tabla 4

\begin{tabular}{|c|c|}
\hline \multicolumn{2}{|c|}{ Equipo y armamento de la Escuela Industrial Militar } \\
\hline Fusiles Chassepott & 200 \\
\hline Porta fusiles & 200 \\
\hline Espadas & 8 \\
\hline Porta espadas & 8 \\
\hline Marrazos & 200 \\
\hline
\end{tabular}




\begin{tabular}{|c|c|}
\hline Cartuchos & 200 \\
\hline Capotes & 200 \\
\hline
\end{tabular}

Fuente: Estado del Armamento, vestuario y equipos de la Escuela Industrial Militar. 15 diciembre 1891. (AHESLP. SCG.1891.1).

El equipo y armamento de la Escuela Industrial Militar para 1901 se componía de cincuenta y cuatro fusiles Remington, cincuenta y seis Chassepott, y ochenta y tres de varios sistemas que servían para instrucción de los alumnos. Además de cuarenta y dos bayonetas y once marrazos. (POESLP, Memoria presentada al Congreso del Estado de San Luis Potosí, por el gobernador constitucional, Blas Escontría, relativo a las actas correspondientes al periodo de septiembre 1899 a agosto 1901).

Sobre los procedimentos disciplinarios el espacio escolar tuvo una función fundamental. A partir de la interpretación de mismo se puede percibir cómo cada lugar de la Escuela Industrial Militar tenía una función simbólica, lo cual refleja lo que Foucault llamó el arte de las distribuciones, es decir, como en determinado espacio se ejercían dispositivos o símbolos para formar en la obediencia, la disciplina y para obtener el control social. (Foucault, 2002: 79-81). Cada espacio del plantel tenía una función simbólica; tanto las aulas escolares como las áreas de producción, las zonas de descanso o recreación, el sitio punitivo o área de calabozos, tenían un uso que iba más allá de simples muros de la institución, en donde se ejecutaban las estrategias para formar en los alumnos el hábito del trabajo, la higiene, disciplina y moral, principios fundamentales de la política educativa porfiriana.

Desde el punto de vista pedagógico el espacio tiene una función trascendental ya que a través de éste se forma la "disciplina racional". Es decir, la formación de la disciplina del tiempo en los alumnos. La disciplina racional estaba enfocada a inculcar en los menores la disciplina y el uso del tiempo, con miras a evitar el ocio en su formación. Estas medidas hicieron más complejo el sistema disciplinario, dándole un sentido más militarizado, además de entrenar a los menores en la disciplina del tiempo como parte de los sistemas laborales y sociales que exigía el modelo capitalista.

Edward P. Thompson explica que, a través del surgimiento de la Revolución Industrial, basada en la invención de nuevas herramientas tecnológicas industriales, el crecimiento de la producción y el intercambio comercial, generó la creación de fábricas en las cuales se implementaron horarios laborales, es decir, la invención del tiempo disciplinado, por ello se tendría que moldear el pensamiento de los trabajadores y de la sociedad en general. La invención del tiempo disciplinado también se llevó a cabo en las escuelas, en donde a través de la disciplina, puntualidad y aprovechamiento del tiempo los alumnos se prepararían para su interacción en el escenario laboral. (Thompson, 1979: 239-293). 


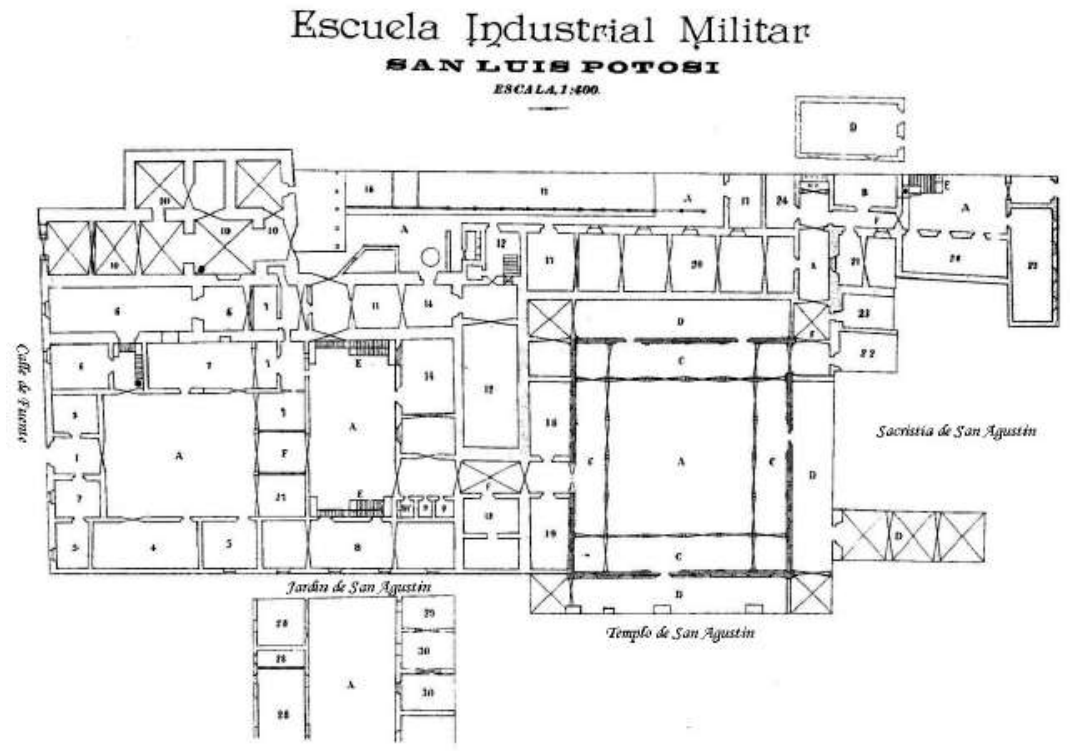

Imagen V. Plano de la Escuela Industrial Militar, ca, 1898-1900.

Fuente: Colección de Memorias e Informes de gobierno, Memorias presentada al Congreso del Estado de San Luis Potosí, por el gobernador constitucional, Blas Escontría, relativo a las actas correspondientes al periodo de agosto de 1898, al mismo mes de 1899. (AHESLP)

Distribución del espacio

1. Vestíbulo

2. Dirección

3. Contaduría

4. Taller de Encuadernación

5. Prefectura

6. Departamento de Tipografía

7. Ídem de Litografía

8. Escuela Instrucción Primaria

9. Calabozos

10. Departamento de Mecánica

11. Ídem de Fundición

12. Ídem de Herrería

13. Ídem de Zapatería

14. Ídem de Hilado y Tejidos

15. Ídem de Canto y Música Ídem de Telegrafía

16. Ídem de Teneduría de libros

17. Ídem de Carpintería

18. Clases de Dibujo

19. Bodega

20. Comedor
21. Cocina

22. Guarda Instrumentos de Música

23. Guardarropa

24. Almacén de Leña

25. Ídem de artefactos

26. Enfermería

27. Departamento de Fotografía

28. Ídem de Carrocería
A-Patios

B-Baños

C-Corredores

D-Dormitorios

E-Escaleras

F-Pasillos

G-Pozos

W.C-Escusados 
En el plano se puede observar como estaba distribuido el espacio de la escuela y la función del mismo. El espacio se puede dividir en escolar, (educación elemental), aprendizaje industrial (áreas de talleres y producción), punitivo (calabozo), de mejoramiento físico y aprendizaje del arte militar (patios de la institución, y el llano de paredes).

De acuerdo con el reglamento de la institución se pueden distinguir la enseñanza del tiempo disciplinado y la función del espacio. Por ejemplo, como ya se dijo, a partir de las cinco de la mañana que se tocaba la diana, los alumnos se formaban en cuadrillas y se les pasaba lista. Enseguida tenían media hora para asearse y limpiar sus dormitorios (espacios de descanso). Cumplida la media hora pasaban al patio a tomar la instrucción militar y los ejercicios de gimnasia (espacios de disciplina y mejoramiento físico).

Los alumnos que no cumplieran con el tiempo establecido, que no tuvieran buena conducta o que no asearan bien su persona o habitaciones, eran castigados con un día en el calabozo (espacios de punitivos y disciplinarios).

El espacio para la educación industrial era ocupado por los talleres. Ahí se preparaba a los alumnos en el manejo de máquinas, fabricación de distintas mercancías y disciplina laboral representada por el cumplimiento de horarios, aprovechamiento del tiempo, acatamiento de órdenes, buen comportamiento y la fabricación en tiempo y forma. Es decir, se preparaba de forma integral a los futuros trabajadores dentro de los estándares laborales.

El espacio punitivo fue utilizado por las autoridades de la Escuela Industrial Militar como el mecanismo con el cual se corregía a los alumnos de mala conducta y desertores. A través del castigo se pretendía corregir, pero también amedrentar a los alumnos para impedir el mal comportamiento.

Según los reglamentos de la institución, los alumnos que tenían mala conducta no salían a los paseos dominicales y eran castigados según la gravedad de la falta con las penas siguientes: reprensión en el calabozo o en presencia de los demás alumnos. O bien se les castigaba poniéndoles a trabajar en el aseo de la escuela, talleres o plazas públicas; también tenían que realizar limpieza y guardias dobles en plazas públicas y edificios de gobierno. No obstante, a los alumnos por su "moralidad, aplicación, asistencia, puntualidad a clases y talleres", se les premiaba con la salida a paseos dominicales y se les gratificaba con pequeñas cantidades monetarias. (AHESLP, Colección de leyes y decretos, 1877-1902. Reglamento Económico de la Escuela Industrial Militar. 1-19).

A los alumnos "rijosos, heridores, obscenos, rateros", se les imponían castigos más severos, consignándolos a la autoridad política para su arresto y castigo en lo privado. (AHESLP, Colección de leyes y decretos, 1877-1902. Reglamento Económico de la Escuela Industrial Militar. 1-19). Los castigos más frecuentes se daban por la deserción escolar, lo cual era castigado con arresto cuando lograban aprehender a los alumnos desertores. Por ejemplo, 
Domingo Silva, originario de San Miguel Allende, Guanajuato, se matriculó en la Escuela Industrial Militar y en 1889 "se fugó del plantel escalando las tapias," por lo que el gobernador Carlos Díez Gutiérrez solicitó su aprehensión, considerando que los alumnos de la Industrial Militar eran estimados como soldados y la fuga de alumnos del plantel era castigada como deserción. (Periódico El Foro, el diario de legislación y prudencia. México, núm. 25, 6 de agosto 1890).

No obstante, la madre de Silva, María Josefa Escobar, solicitó al juzgado del distrito de Guanajuato el amparo de su hijo, el cual fue concedido, debido a que la fracción 2 del artículo 112 de la Constitución Federal sólo consideraba soldados a los integrantes de las guardias y ejército nacional, por lo que los alumnos de las escuelas industriales militares no formaban parte del ejército nacional, aunque recibían instrucción militar.

Acerca de este tema, resalta que la normatividad potosina violentaba la Constitución Federal, ya que, según la ley del 30 de mayo de 1884 sobre Instrucción Pública se estipuló que, tanto en la Escuela Industrial Militar como en la Escuela Normal para Profesores, se formarían ciudadanos al servicio de las armas del Estado, por lo cual los alumnos pertenecientes a los escuadrones de dichas instituciones formaban parte de la artillería de la entidad. (POESLP, 21 de septiembre, 1885).

Se puede suponer que los fuertes castigos y la dura disciplina militar impuesta a los alumnos generaban que estos se fugaran del establecimiento. Algunos que integraban los escuadrones de la Escuela Industrial Militar huían estando francos y también aprovechaban la noche para fugarse. Ese fue el caso en 1893 de los soldados de la $1^{a}$ compañía: "Guadalupe Díaz de Lara, Rafael Díaz de Lara, Miguel Montiel, y Ciriaco Rubio, quienes escalaron las tapias del establecimiento en las altas horas de la noche". (AHESLP, SCG, 1893.4).

La deserción constante de los alumnos provocó que estos fueran vigilados día y noche por rondines militares del 3er regimiento del Estado quienes pasaban revista. Incluso cuando estos se encontraban enfermos en el hospital civil se les vigilaba las 24 horas para evitar que se fugaran. Esto debido a que en varias ocasiones los alumnos se escapaban estando en curación, como se muestra en el siguiente comunicado:

Habiéndose repetido en varios casos la fuga de alumnos de la Escuela Industrial Militar estando en curación en el Hospital civil, el Gobernador ha tenido a bien acordar se recomiende a la administración de dicho Hospital se vigile y prevenga en lo sucesivo para evitar tales fugas ponga el mayor cuidado empleando toda la vigilancia posible. (AHESLP, SGG. 1889.2).

Cuando los alumnos desertaban, de inmediato se exhortaba a los batallones del estado y a la policía montada para capturarlos y reintegrarlos al plantel. Como fue el caso del alumno 
"Candelario Ramírez, quien fue aprehendido y consignado al calabozo del plantel, hasta nueva orden" en 1891. (AHESLP, SGG, 1892.2). Posteriormente desertó de nueva cuenta, junto a otro alumno llamado Vicente Murguía, estando francos.

Es importante señalar que los castigos a los alumnos desertores o indisciplinados incluían en algunos casos golpes en lo privado, lo que ocasionaba graves daños a la salud y en algunas ocasiones la muerte. El alumno Macario Orta falleció a causa de los golpes que le dio el sargento del tercer batallón Constantino Aguilar. De acuerdo, al reporte del mismo sargento, el alumno había intentado fugarse en varias ocasiones y constantemente desobedecía sus órdenes, por lo que fue castigado a base de "palos en lo privado". Según la abuela de Macario Orta, este castigo había propiciado la muerte de su nieto, por lo que exigía al Gobernador que fuera castigado el sargento Aguilar. Dicho caso apareció publicado en el periódico El Popular, y se tituló "Un Crimen en la Escuela Industrial Militar de San Luis Potosí". (Periódico El Popular, 30 de diciembre 1898).

En dicha publicación se mencionaba que el alumno interno Macario Orta de la Escuela Industrial Militar "recibió del sargento Aguilar una paliza tan temible que le fracturó un brazo y le produjo una sensible conmoción cerebral por los golpes dados en la cabeza postrándolo en la cama y a consecuencia de eso fallecido después." (Periódico El Popular, 30 de diciembre 1898). El director de la Escuela Industrial Militar Ramón Ceballos, menciona en su reporte que "el 25 de noviembre se presentó en el plantel la señora Julia Salazar manifestando que su nieto Macario Orta llegó a su casa golpeado y había fallecido por los golpes que recibió en la escuela" (Periódico El Popular, 30 de diciembre 1898).

Mientras el reporte del médico Gustavo López, quien atendió al herido, mencionaba que "encontró a Macario Orta casi moribundo, por una meningitis ocasionada por los golpes lo que le ocasionó la muerte". (AHESLP, SGG, 1898.10). Cabe señalar que el expediente no menciona si el sargento Aguilar fue castigado por dicho acto.

Cabe señalar que la supuesta disciplina aplicada en la institución fue criticada por la prensa. En el periódico El Estandarte se decía que en la Escuela Industrial Militar no se aplicaba la disciplina, ni se formaban hombres de bien como se decía, ya que en ocasiones "se veía a los alumnos portando el uniforme irse bamboleando en las aceras, por efecto del licor". (Periódico El Estandarte 11 de octubre 1885). También el Inspector General de Salubridad pública del estado comunicaba al director, que con frecuencia se veía a los alumnos del plantel en la vecindad Ilamada "las mujeres bravas" donde se verificaban bailes y diversiones ilícitas a las cuales acudían los alumnos de la Escuela Industrial Militar. El castigo por parte de la institución a los alumnos que portaban el uniforme y que se les veía tomando bebidas embriagantes fue a base de palos en lo privado y encierro en el calabozo, por una o dos semanas. (AHESLP, SGG, 1898.10).

Dichas situaciones hacen entrever que no precisamente la disciplina militar y la moralidad eran del todo aplicadas por los alumnos. Quizá era el gran número de internos que formaban 
parte de la tropa lo que impedía tener control disciplinario en todos los alumnos. O bien, que la supuesta disciplina y moralidad de la cual se hablaba en los discursos oficiales pronunciados por los gobernadores potosinos en relación al adelanto que esta institución, era solamente parte del discurso y no de las prácticas cotidianas en la institución, ya que en la mayor parte de la correspondencia del director de la institución refiere que los alumnos desertaban a las altas horas de la madrugada, o estando francos. También había ocasiones en las que se encontraba a los alumnos con aliento alcohólico o con bebidas embriagantes en el plantel, por lo que eran llevados al calabozo. (AHESLP, SGG, 1898.10).

Es importante mencionar que había padres de familia que precisamente matriculaban a sus hijos en la Escuela Industrial Militar porque consideraban que la disciplina militar, ayudaría a sus hijos a formarlos "en el trabajo, disciplina y moralidad, lo que formaría hombres de bien". (AHSLP, SCG, 1890.36).

La Escuela Industrial Militar fue criticada por algunos medios de la prensa potosina entre ellos el periódico El Estandarte, en el cual se menciona que en dicha institución el gobierno estatal sólo jugaba a "formar soldaditos a su servicio y afición." Según el mismo diario, existía un temor "entre las clases del pueblo, ya que a sus hijos los tomaba la policía secreta para ponerlos de soldados en la Escuela Industrial Militar". (AHESLP, SCG. 1898.10).

\section{Conclusiones}

Para el gobierno de San Luis Potosí la Escuela Industrial Militar representó el modelo educativo que formaría el tipo de ciudadano que el país requería, con talento y actitudes para el trabajo, principio que mejoraría la condición social de los niños y jóvenes de sectores vulnerables. Es importante mencionar que la disciplina militar fue un mecanismo que correspondió a una forma de pensar influenciada por el positivismo lo cual derivó en otorgar al Estado una función como interlocutor para educar a las clases menesterosas hacia el bien común.

El éxito de dicho modelo es cuestionable debido a que la educación militar provocaba la deserción de los alumnos por la rígida disciplina. Sin embargo, hubo alumnos a los que la instrucción militar les venía bien ya que a través de esta disciplina lograron emplearse como sargentos y generales en las tropas del estado. También hubo alumnos que continuaron su preparación en el Colegio Militar de la ciudad de México. Dichas cuestiones dejan entrever que más allá de los mecanismos de disciplina empleados, pudo haber sido un asunto de disposición por parte de los alumnos, no sin dejar de lado que los castigos empleados por las faltas de conducta o la inmoralidad fueron bastante duros lo que ocasionaba en algunos estudiantes un buen comportamiento y que permanecieran en el plantel hasta concluir su educación elemental y dominaran sus oficios. 
La militarización de la educación por parte del régimen porfiriano, fue un mecanismo con el cual el gobierno concibió la educación de la niñez y juventud, a quienes se trató de encauzar en un sistema disciplinario y también formar en ellos el patriotismo, tema trascendental debido a que se consideraba que desde la niñez se tendría que fomentar el amor y el respeto a la patria.

La instrucción militar también tuvo como fin mejorar la condición física de la niñez, es decir formar cuerpos vigorosos y saludables. El hecho de que la Escuela Industrial Militar se militarizara, muestra la visión que tuvo el gobierno hacia la forma como se debería educar a los futuros ciudadanos, además de las estrategias utilizadas por el Estado para integrar ciudadanos patriotas que fueran fieles a la nación y sus instituciones.

Entre los aportes de este artículo apunto cómo fue el proceso de la militarización de la educación, cuestión que fue propuesta en primera instancia por el General Bernardo Reyes, quien durante su estancia en San Luis Potosí, propuso al gobernador Carlos Díez Gutiérrez que se impulsara este método, lo cual generó que la Escuela de Artes y Oficios "Benito Juárez" se transformara en Escuela Industrial Militar, siendo la primera institución en donde después del Colegio Militar, se instruyera a los alumnos el uso de armas y tácticas militares.

Este tema es significativo debido a que la educación se fue militarizando en razón de ir formando soldados profesionales con amor a la patria. Para Bernardo Reyes la militarización de la educación ayudaría a desarrollar el patriotismo y la formación de ciudadanos disciplinados y trabajadores. Retomando a Foucault, desde el poder se instituyen mecanismos y dispositivos que ejercen dominación y control social. Es decir, la formación de la disciplina y el castigo son usados por la autoridad como tácticas políticas que generan una acción social de manera controlada. A través de estas estrategias disciplinarias se va formando la obediencia social, la disciplina laboral y apego al poder y sus instituciones.

Se puede considerar que la instrucción militar fue dando resultados ya que hubo alumnos de la Escuela Industrial Militar que se incorporaron a los regimientos de San Luis Potosí, y otros continuaron su preparación en el Colegio Militar.

Sería importante dar seguimiento a los soldados que se formaron en la Escuela Industrial Militar quienes pudieron incorporarse al ejército mexicano, o a caudillos revolucionarios durante la Revolución Mexicana, y si continuaron su trayectoria dentro de la milicia, temas que ya no se abordaron en esta investigación. 


\section{Archivos}

AGN, Archivo General de la Nación. IPBA, Ramo Instrucción Pública y Bellas Artes Ciudad de México, México.

AHESLP, Archivo Histórico del Estado de San Luis Potosí. SGG, Fondo Secretaría General de Gobierno

(1874). Caja Memorias e informes de Gobierno. Memoria de los actos de toda su administración presentada a la Legislatura del Estado de San Luis Potosí, del ciudadano general Mariano Escobedo 1874. San Luis Potosí, San Luis Potosí, México.

AHESLP, Archivo Histórico del Estado de San Luis Potosí. ASLP, Fondo Ayuntamiento.

AHESLP, Archivo Histórico del Estado de San Luis Potosí. SGG, Fondo Secretaría General de Gobierno.

San Luis Potosí, San Luis Potosí, México.

AHIDC, SLP. Archivo Histórico del Internado Damián Carmona. San Luis Potosí.

\section{Referencias hemerográficas}

Bailón Vázquez, Fabiola (2012), "La Escuela Correccional de Artes y Oficios de Oaxaca, 1889-1901" en Estudios de Historia Moderna y Contemporánea de México, núm. 44, julio-diciembre, Universidad Nacional Autónoma de México, México.

Ramírez Rancaño, Mario (2008), "La logística del ejército federal: 1881-1914" en Estudios de Historia Moderna y contemporánea de México, núm. 36, julio-diciembre, Universidad Nacional Autónoma de México, México.

Sánchez Martínez, Berenice (2014), "La enseñanza del dibujo en San Luis Potosí durante el porfiriato" en Revista de El Colegio de San Luis, vol. 4 no. 8, julio-diciembre San Luis Potosí, México.

\section{Referencias bibliográficas}

Bazant, Mílada (1993), Historia de la educación durante el Porfiriato, El Colegio de México, México.

Bourdieu, Pierre. y Jean-Claude. Passeron (1996), La Reproducción: elementos para una teoría del sistema educativo. Fontamara, México.

Castillo Troncoso, Alberto (2006), Conceptos, imágenes y representaciones de la niñez en la ciudad de México, 1880-1920, El Colegio de México/ Instituto de Investigaciones Doctor José María Luis Mora, México.

Estadísticas Sociales durante el porfiriato (1956), Secretaría de Economía/Dirección General de Estadística./ Talleres Gráficos de la Nación, México.

Fernández Justino (1902), Memoria que el Secretario Justino Fernández presenta al Congreso de la Unión. Antigua Imprenta de J.F. Jens, Sucesores, México.

Foucault, Michel (2002), Vigilar y Castigar, Nacimiento de la prisión. Buenos Aires, Siglo XXI Editores, Argentina.

Muro, Manuel (1899), Historia de la Instrucción Pública en San Luis Potosí, San Luis Potosí, M. Esquivel y Compañía, México.

González Villalobos, Verónica (2010), Reclutamiento y trayectorias escolares de los alumnos de la Escuela de Artes y Oficios del Estado de Jalisco (1842-1910), Universidad de Guadalajara, Guadalajara.

Gonzalo Navarro, Moisés (1957), en Daniel Cosío Villegas (Dir), Historia Moderna de México, El Porfiriato. La vida social, Editorial Hermes, México. 
Ramírez, Georgina (2011), Educar al cuerpo en el porfiriato (1900-1910), una mirada a través de las revistas pedagógicas. Tesis Maestría en Pedagogía, Facultad de Filosofía y Letras/UNAM, México.

Ramírez Rancaño, Mario (2010), La justicia durante el porfiriato y la revolución 1898-1914. Los amparos entre el ejército federal; 1898-1914. Suprema Corte de Justicia de la Nación, México.

Schultz, Theodore (1985), Investing in people. The economics of population quality, Editorial Ariel, S.A., España.

Speckman, Elisa (2005), "Infancia es destino. Menores delincuentes en la ciudad de México (18841910)", en Claudia Agostoni y Elisa Speckman (eds.), De normas y transgresiones. Enfermedad y crimen en América Latina (1850-1950), Universidad Nacional Autónoma de México, México.

Thompson, Edward Palmer (1979), Tradición, revuelta y consciencia de clase, Editorial Crítica, Barcelona.

Tenorio Trillo, Mauricio (1998), Artilugio de la nación moderna. México en las exposiciones universales, 1880-1930, FCE, México.

Torres Septién, Valentina (1998), "Notas sobre urbanidad y buenas maneras de Erasmo al manual de Carreño" en Pilar Gonzalbo Aizpuru (coord), Historia y Nación. Historia de la educación y enseñanza de la historia. El Colegio de México, México. 